\title{
Understanding Engineering Students' Behaviours when Writing Group Report using Wiki
}

\author{
Iwan Handoyo Putro ${ }^{1, *}$, Petrus Santoso ${ }^{1}$, Handry Khoswanto ${ }^{1}$, Handy Wicaksono ${ }^{1}$, and \\ Ivan Surya Hutomo ${ }^{2}$ \\ ${ }^{1}$ Electrical Engineering Department, Petra Christian University, Jl. Siwalankerto No.121-131, \\ Surabaya 60236, East Java, Indonesia \\ ${ }^{2}$ National Chiao Tung University, Daxue Road, East District, Hsinchu City, 30010 Taiwan, ROC
}

\begin{abstract}
The ability to operate as a group in workplace has become a key requirement in the globally connected workplace. As such, higher education institution needs to provide collaborative work experience in order to prepare their graduates to be ready for real world organization. In most situation, students learn to work collaboratively in an online environment via Wiki. This free tool allows student to write, edit and format manuscript in online manner. However, when working in a group, students does not always prepare to cope with the group dynamics. Therefore, students encounter challenges and difficulty to operate as a group. The aim of this study is to investigate whether students develop unique behaviour when trying to complete the group assignment. The research result reveals that group assignment does not always be a perfect working environment and they as consequences they develop several group behaviours in order to develop unique behaviour in order to be successfully complete their group task.
\end{abstract}

Keywords: Collaborative learning platform, collaborative writing, group work, online environment, unique behaviour.

\section{Introduction}

In the class, lecturer usually introduce the collaborative skill for their students through group work assignment. Students are assigned in the group to work on a certain task; often without prior knowledge to cope with the group dynamics (for instance: dispute, weak leadership, unbalance work, freeriding) [1,2]. As a result, this group work assignment does not always end up with a happy story, instead it can give students traumatic experience that possibly prevent them to behave properly in their future employment.

This paper is a continuing work from previous research. Total of 28 students from Electrical Engineering Department were working collaboratively to complete a group task. After completing the task, students were given questionnaire to fill. The result from this questionnaire along with class observation conducted during semester were analysed. The result indicates that students developed several behaviors when working in the online group

*Corresponding author: iwanhp@petra.ac.id 
using Wiki in attempt to address their assignment successfully.

\section{Review of the literature}

Wiki has been extensively adopted as an online platform for learning collaboratively. Wiki is a free website that allows group members to write, edit, and delete content in a collaborative manner [3, 4]. This collaborative learning platform enables students to mimic workplace experience in which employee working together and share their contribution to complete a specific goal.

Wiki have cemented their way into classroom in which students can practice contributing their writing towards more democratic process which accommodating various users' roles (i.e. editor and writer). Second, through the use of Wiki, it allows other group members to provide revisions for further manuscript refinement, and finally this leads to the final group product that can be more accurate and easier to navigate $[5,6]$.

Studies on how students' behaviours in a group has been initiated to provide better understanding for the instructor to deal with the group dynamics. Group dynamics is the process that involve members' interactions to overcome any distraction during group task (i.e. conflict, task division, etc) [7]. It is important for the students when working in the group to cope with the group dynamics issue as group does not start normally as it is initiated $[8,9]$. When students do not have prior experience when working in a group, a success story sometimes can be just a coincidence or perhaps a group member taking over group burden to save their grade. As such, it is interesting to investigate what can of students' behaviour when they were working together as a group.

\section{Methodology}

This research is a follow up to a previous study on developing tools to support group assessment in wiki [10]. In this project, 28 male students from Electrical Engineering Department were voluntarily asked to participate in an online group writing report task using Wiki. Students were assigned into a group of three or four students. They worked during semester to create a Laboratory report on Basic Electronics course.

This research is driven by following three research questions:

i. Did students aware that group final product does not present individuals contribution?

ii. Were all group members provide fair contribution to the task?

iii. When working in the group, did students develop unique behaviour?

As it was mentioned previously, this research aim is to get students' behaviour when working as a group. As such no text analysis was made in this study. Data collected from the questionnaire combined with the informal observations and students' log book were analysed to get insight into the group dynamics and students' roles and behaviours during assignment completion.

\section{Results and discussion}

\subsection{Research question 1: Did students aware that group final product does not present individuals contribution?}

This section provides the results and discussion from this project. Table 1 provides excerpt of data from the questionnaire circulated to the group members. The questionnaire was designed using 5-likert chart scale ranging from strongly agree to strongly disagree. These 
three questions are related to (i) group assessment, (ii) group member's perception toward others' contribution, and (iii) decision made when dealing with group dynamic.

Table 1. Summary of group work questionnaire.

\begin{tabular}{|c|l|c|c|c|c|c|}
\hline No & \multicolumn{1}{|c|}{ Question } & $\begin{array}{c}\text { Strongly } \\
\text { Agree }\end{array}$ & Agree & Neutral & Disagree & $\begin{array}{c}\text { Strongly } \\
\text { Disagree }\end{array}$ \\
\hline 1 & $\begin{array}{l}\text { Group product } \\
\text { does not present } \\
\text { individuals } \\
\text { contribution }\end{array}$ & 1 & 15 & 7 & 5 & 0 \\
\hline 2 & $\begin{array}{l}\text { There is group } \\
\text { member who did not } \\
\text { provide contribution }\end{array}$ & 2 & 11 & 6 & 8 & 1 \\
\hline 3 & $\begin{array}{l}\text { I would rather take } \\
\text { group responsibility } \\
\text { ather than share it to } \\
\text { incompetent group } \\
\text { member }\end{array}$ & 0 & 17 & 5 & 5 & 1 \\
\hline
\end{tabular}

It can be seen that about half of the students aware that the group product does not always present the individuals' contribution. It indicates that some students who provide less contribution might get benefit from other students who create bigger contribution to the task. This phenomenon called free- riding in which group members enjoy the benefits from others contribution. He or she contribute so little that when the group grade is given to all group members that the grade would unfair.

From the observation and students' log book analysis, the free-riding phenomenon does not always relate to the amount of work provided but can also be manifested in the form of lack of commitment and disconnecting with the group work. Several students were involved in some student's union and activities that prevent them to provide adequate contribution to the group. Other students were not active in the group. They made no contact with the other group members and appear at the end of the assignment date. As such, other group members have to take over the work for the sake of the assignment completion and causing group conflict. This leads to the second research question below.

\subsection{Research question 2: Were all group members provide fair contribution to the task?}

Although students aware that group grade does not reflect individuals' contribution, interestingly only $39 \%$ of the group members agree that not all group members provide fair contribution to the group (see Table 1 question number 2). In addition, eight students disagree to this statement. It seems that students get benefit from self-group assigned. In this study, students can choose their own group members. As consequences, they pick up partner who can work with them rather than students who does not familiar with. A few groups might suffer as there is no more students available and they have to make group with the students that were left behind. This explains why less students feel that their group members do not provide fair contributions.

While it seems that self-group assigned is better solution for group work assignment, students that left behind might feel from being neglected by the cohort. From the log book analysis, this type of students writes "I feel neglected and other group members did not give me a task to do". It seems that Lecturer might understand the class situation prior giving the group assignment so that every student can provide his/her best contributions apart from dealing with the group dynamics. 


\subsection{Research question 3: When working in the group, did students develop unique behaviour?}

Table 2. Students behaviours in the group

\begin{tabular}{|l|l|}
\hline \multicolumn{1}{|c|}{ Behaviours } & \multicolumn{1}{c|}{ Description } \\
\hline Taking over burden & $\begin{array}{l}\text { Group member that doing huge amount of work to save the } \\
\text { group }\end{array}$ \\
\hline Withdrawing & Group member who does not participate in the group. \\
\hline Aggressive & $\begin{array}{l}\text { Group member who often disagrees with others in } \\
\text { appropriate manner. }\end{array}$ \\
\hline Working in silence & Group member that willing to work without questioning. \\
\hline
\end{tabular}

Table 2 shows students' behaviours that developed during the online group writing task was conducted. These four types of behaviours were taken from both informal observation and students' logbook analysis. These behaviours emerged in the observation are: taking over burden, withdrawing, aggressive and working in silence.

From Table 1, it can be seen that 17 students were willing to take group responsibility to save their group performance. This figure represents $60 \%$ of the total students who participated in this study. This indicates that although they choose their own group member, there were difficulty happened during the task completion. As it was coined in the seminal works of Tuckman Group Stage Development [11], after forming the group most group suffer from storming stage in which they starts to challenge each other's ideas, gaining trust, and resolve differences. Some groups can survive this stage so they can continue to perform in the group, others were facing a never-ending debate before lost their time.

From this situation, several behaviours have been identified. First, students were willing to take over burden for the sake of group task completion. This behaviour can emerge from poor group condition in which some members disconnect with the group and does not provide fair contribution to the task.

Second behaviour is withdrawing. Students who feel neglected by their peers might make decision to simply withdraw from the group. As such, Lecturer need to continuously monitor group performance in order to reduce the class dropout figure.

The third behaviour is aggressive group member. When the group is in the storming stage, this type of behaviour may cause longer delay before norming and performing stage. An aggressive group member often talkative, attention monopoly and dominating the group. A student wrote in his logbook "he always dominating the group... his opinion and idea must be obeyed... he treats others as his employee". When providing idea and suggestion is beneficial to the group performance, group members need to accept that his idea cannot be implemented in a particular project.

\section{Conclusion}

The present study investigates what students' behaviour that might appear during online group work assignment. This information is important to gain better understanding on how group work should be monitored, managed and assessed. This research reveals that (i) students need to be prepared better prior to group work; (ii) monitoring and feedback need to be done to ensure fair contribution; (iii) educators need to anticipate several group behaviours that appears during group assignment.

\section{References}

1. A.J. Ferrier. Compass: Journal of Learning and Teaching, 10,1:1-8(2017). https://journals.gre.ac.uk/index.php/compass/article/view/352 
2. H. Caple, M. Bogle. Assessment \& Evaluation in Higher Education, 38,2:198210(2013). https://www.tandfonline.com/doi/abs/10.1080/02602938.2011.618879

3. R. Davidson, J. Learn. Des., 5,2:38-49(2012). https://files.eric.ed.gov/fulltext/EJ1083925.pdf

4. P.I. Vidal-Carreras, J.P. Garcia-Sabater, J.J. Garcia-Sabater, M.R. Perello-Marin. Wiki as an activity learning. In: Closing the gap between practice and research in industrial engineering. Verlag: Springer International Publishing (2018). pp. 381-388.

https://www.springerprofessional.de/wiki-as-an-activity-learning/14223070

5. M. Biasutti. Computers \& Education, 111:158-171(2017). https://www.sciencedirect.com/science/article/abs/pii/S0360131517300787

6. H. Meishar-Tal, P. Gorsky, Open Learning: The Journal of Open and Distance Learning, 25,1:25-35(2010). https://eric.ed.gov/?id=EJ880681

7. D.R. Forsyth. Group dynamics. Belmont, Canada: Cengage Learning (2014). p. 752. https://books.google.co.id/books/about/Group_Dynamics_6th_ed.html?id=q3R1ngEAC AAJ\&redir_esc $=$ y

8. R. Brown. Group processes: Dynamics within and between groups. Oxford, United Kingdom: Wiley-Blackwell (2001). p. 442. https://www.amazon.com/Group-ProcessesDynamics-Within-Between/dp/0631184961

9. A.R. Finegold, L. Cooke. The Internet and Higher Education, 9,3:201-215(2006). https://www.sciencedirect.com/science/article/abs/pii/S1096751606000340

10. I.H. Putro, P. Santoso, H. Khoswanto, H. Wicaksono, Journal of Physics: Conf. Series, 1165:1-9(2019). https://iopscience.iop.org/article/10.1088/17426596/1165/1/012018/pdf

11. D.A. Bonebright. Human Resource Development International, 13,1:111-120(2010). https://www.tandfonline.com/doi/abs/10.1080/13678861003589099 